\title{
COMPACTAÇÃO EM UM LATOSSOLO VERMELHO DISTROFÉRRICO E SUAS RELAÇÕES COM O CRESCIMENTO RADICULAR DO MILHO ${ }^{(1)}$
}

\author{
Anderson Cristian Bergamin ${ }^{(2)}$, Antonio Carlos Tadeu Vitorino ${ }^{(3)}$, \\ Julio Cezar Franchini ${ }^{(4)}$, Cristiano Márcio Alves de Souza ${ }^{(5)}$ \& Fábio \\ Régis de Souza ${ }^{(2)}$
}

RESUMO

A compactação dos solos agrícolas, em decorrência da intensificação da agricultura com elevado tráfego de máquinas, vem se tornando, nos últimos anos, fator limitante ao crescimento e desenvolvimento das plantas. Assim, o objetivo deste trabalho foi avaliar, em um Latossolo Vermelho distroférrico muito argiloso, cultivado em sistema plantio direto, a influência da compactação induzida pelo tráfego de um trator agrícola MF 292 (105 cv), com massa total de $5 \mathrm{Mg}$ e com pressão de inflação de $96 \mathrm{kPa}$ nos pneus dianteiros (14.9-24 R1) e $110 \mathrm{kPa}$ nos pneus traseiros (18.4-34 R1), sobre a densidade, porosidade, resistência do solo à penetração e estabilidade de agregados, bem como as consequências sobre o crescimento radicular da cultura do milho. O estudo foi realizado na Fazenda Experimental de Ciências Agrárias da UFGD, no município de Dourados, MS. O delineamento experimental utilizado foi de blocos casualizados, com cinco repetições. Os tratamentos foram constituídos por estados induzidos de compactação, sendo: PD - condição atual que reflete o histórico de oito anos de plantio direto; e plantio direto com compactação adicional por tráfego de trator em uma (PDc1), duas (PDc2), quatro (PDc4) e seis passadas (PDc6). A microporosidade do solo não foi alterada pela compactação adicional. Analisando o sistema radicular do milho, foram observadas reduções nos valores de diâmetro, comprimento e superficie radicular, ocorrendo decréscimo de $85 \%$ no comprimento

\footnotetext{
(1) Parte da Dissertação de Mestrado do primeiro autor apresentada ao Programa de Pós-Graduação em Agronomia da Universidade Federal da Grande Dourados - UFGD. Recebido para publicação em junho de 2009 e aprovado em março de 2010.

(2) Doutorando do Programa de Pós-Graduação em Agronomia da Universidade Federal da Grande Dourados - PPGA/UFGD. Rodovia Dourados-Itahum, Km 12, Caixa Postal 533, CEP 79804-970 Dourados (MS). E-mails: andersonbergamin@hotmail.com; fabioagronomo@yahoo.com.br

(3) Professor Associado da Faculdade de Ciências Agrárias, UFGD. Bolsista do CNPq. E-mail: antoniovitorino@ufgd.edu.br

(4) Pesquisador A da Empresa Brasileira de Pesquisa Agropecuária, Centro Nacional de Pesquisa de Soja. Rod. Carlos João Strass/ Acesso Orlando Amaral, Distrito da Warta, Caixa Postal 231, CEP 86001-970 Londrina (PR). E-mail: franchin@cnpso.embrapa.br

(5) Professor Adjunto IV da Faculdade de Ciências Agrárias, UFGD. Bolsista do CNPq. E-mail: csouza@ufgd.edu.br
} 
radicular, comparando o PD com o PDc6. O aumento da compactação do solo induzida pelo tráfego de trator a partir de duas passadas $(220 \mathrm{kPa})$ promoveu aumento da Ds e redução da Macro e Pt, e a partir de quatro passadas $(440 \mathrm{kPa})$ promoveu aumento da RP de maneira efetiva, até $0,10 \mathrm{~m}$ de profundidade. A macroporosidade do solo é um bom indicador da sua qualidade para avaliações de comprimento e superfície radicular.

Termos de indexação: atributos físicos, comprimento radicular, superfície radicular.

\title{
SUMMARY: INDUCED COMPACTION OF A RHODIC ACRUSTOX AS RELATED TO MAIZE ROOT GROWTH
}

\begin{abstract}
Compaction of agricultural soils due to intensive farming with intense traffic of agricultural machinery has become a limiting factor for crop development in recent years. The objective of this study was to evaluate a Rhodic Acrustox under no-tillage for the influence of compaction on the soil density, porosity, penetration resistance and aggregate stability, and the consequences on corn root growth. Compaction was induced by tractor traffic of MF $292(105 \mathrm{hp})$, with a mass of $5 \mathrm{Mg}$ and pressure inflation of $96 \mathrm{kPa}$ for front tires (14.9-24 R1) and $110 \mathrm{kPa}$ for rear tires (18.4 - 34 R1) in the following treatments: NT - current condition that reflects the history of eight years of no-tillage, no-tillage with additional compaction by tractor traffic in one (NT - 1), two (NT - 2), four (NT - 4) and six passes (NT - 6). Soil microporosity was not affected by additional compaction. The root diameter, length and surface values were reduced, with a decrease of $85 \%$ in root length of NT compared to NT - 6. Increased soil compaction induced by tractor traffic with two passes $(220 \mathrm{kPa})$ or more increased soil density and reduced macroporosity and total porosity, while four passes $(440 \mathrm{kPa})$ or more resulted in an increase in soil penetration resistance to a depth of $0.10 \mathrm{~m}$. Macroporosity is a good indicator of soil quality in assessments of root length and surface.
\end{abstract}

Index terms: physical properties, root length, root surface.

\section{INTRODUÇÃO}

O sistema de plantio direto (SPD) vem sendo praticado por grande parte dos agricultores no Brasil, sendo as culturas produtoras de grãos implantadas principalmente neste sistema. No SPD ocorre revolvimento do solo somente na linha de semeadura, mantendo os restos culturais na superfície e reduzindo a erosão (Llanillo et al., 2006). No entanto, o uso do solo sob esse sistema muitas vezes está associado ao intenso tráfego de máquinas, as quais contribuem para alterar a qualidade estrutural do solo, o que acarreta aumento da compactação (Collares et al., 2006), principalmente em solos com elevados teores de argila (Secco et al., 2004).

No SPD o tráfego de máquinas pode promover compactação superficial do solo (Beutler et al., 2001; Tavares Filho et al., 2001), sendo observados aumentos significativos e prejudiciais da compactação para as plantas, principalmente até $0,20 \mathrm{~m}$ de profundidade (Cardoso et al., 2006), embora o maior estado de compactação seja verificado próximo a $0,10 \mathrm{~m}$ de profundidade (Genro Junior et al., 2004).

Estudos que relatam alterações significativas nos atributos físicos do solo em virtude do seu não revolvimento e do tráfego contínuo de máquinas pesadas e equipamentos agrícolas em solo com umidade elevada são frequentes (Streck et al., 2004; Beutler et al., 2007; Freddi et al., 2007; Collares et al., 2008). Nessas condições, a compactação tem sido indicada como a principal causa da degradação física dos solos pela redução de seu espaço poroso (Raper, 2005). Para Collares et al. (2006), em consequência da compactação, há alteração estrutural do solo devido à reorganização das partículas e de seus agregados, o que aumenta a densidade (Ds) e resistência do solo à penetração (RP) e reduz a macroporosidade (Macro), inibindo assim o crescimento e o desenvolvimento radicular das plantas. Essa resposta das plantas é mais facilmente observada quando ocorre precipitação pluvial irregular no período de cultivo.

A resposta das principais culturas à compactação ainda não é completamente conhecida (Collares et al., 2008). Aumento na compactação reduz o crescimento de raízes devido ao aumento na $\mathrm{RP}$, podendo ocasionar perdas de produtividade nos cultivos agrícolas, por restringir o reservatório de água e nutrientes às raízes (Clark et al., 2003). Alguns estudos têm utilizado a RP e a Ds para avaliar os efeitos dos sistemas de manejo do solo no sistema radicular (Freddi et al., 2007; Collares et al., 2008). Entretanto, não tem sido 
possível estabelecer relações funcionais desses atributos com o crescimento do sistema radicular e a produção das culturas, pois estas são influenciadas pelas complexas interações entre as fases sólida, líquida e gasosa do solo, dificultando a obtenção de valores críticos ao desenvolvimento e produtividade das culturas (Beutler et al., 2004).

As pesquisas realizadas para obter respostas das plantas em solos com diferentes estados de compactação, normalmente, têm sido realizadas em vasos e podem não representar realmente as condições impostas pelo ambiente em campo ao crescimento e desenvolvimento das plantas. Para Foloni et al. (2003), o crescimento radicular do milho em Latossolo Vermelho distroférrico textura média foi prejudicado em $50 \%$ quando a RP foi de $0,75 \mathrm{MPa}$ e totalmente inibido quando esta chegou a 1,4 $\mathrm{MPa}$. O valor de 2,0 MPa tem sido utilizado como limite crítico de RP (Taylor et al., 1966), porém esse valor vem sendo questionado por outros autores (Beutler et al., 2004; Serafim, 2007), o que sugere a necessidade de mais estudos.

Devido à grande dificuldade em avaliar em campo a compactação do solo causada pelo tráfego de máquinas agrícolas, poucos estudos têm sido realizados. No entanto, é necessário conhecer os estados de compactação que reduzem o crescimento do sistema radicular das plantas, visando ao uso do solo de forma eficiente e sustentável, minimizando os efeitos adversos da compactação do solo.

Nesse contexto, o objetivo deste estudo foi avaliar diferentes estados de compactação em um Latossolo Vermelho distroférrico muito argiloso em SPD, induzidos pelo tráfego de um trator, por meio de atributos físicos e suas consequências sobre o sistema radicular da cultura do milho.

\section{MATERIAL E MÉTODOS}

O estudo foi realizado na Fazenda Experimental de Ciências Agrárias da Universidade Federal da
Grande Dourados (UFGD), no município de Dourados, MS, no ano agrícola de 2007/2008. O local situa-se em latitude de $22^{\circ} 14^{\prime} 08^{\prime} \mathrm{S}$, longitude de $54^{\circ} 59^{\prime} 13^{\prime}$ W e altitude de $434 \mathrm{~m}$. O clima é do tipo Cwa, segundo a classificação de Köppen (Figura 1).

Foi utililzado um Latossolo Vermelho distroférrico, cuja composição granulométrica, determinada pelo método da pipeta (Embrapa, 1997), foi: $644 \mathrm{~g} \mathrm{~kg}^{-1} \mathrm{de}$ argila, $203 \mathrm{~g} \mathrm{~kg}^{-1}$ de silte e $153 \mathrm{~g} \mathrm{~kg}^{-1}$ de areia nos primeiros $0,20 \mathrm{~m}$. As características químicas foram: $\mathrm{pH}\left(\mathrm{H}_{2} \mathrm{O}\right)=5,7 ; \mathrm{Ca}^{2+}=69,2 \mathrm{mmol}_{\mathrm{c}} \mathrm{dm}^{-3} ; \mathrm{Mg}^{2+}=$ $31,0 \mathrm{mmol}_{\mathrm{c}} \mathrm{dm}^{-3} ; \mathrm{Al}^{3+}=0,0 \mathrm{mmol}_{\mathrm{c}} \mathrm{dm}^{-3} ; \mathrm{H}+\mathrm{Al}=$ $58,0 \mathrm{mmol}_{\mathrm{c}} \mathrm{dm}^{-3} ; \mathrm{P}=7,0 \mathrm{mg} \mathrm{dm}^{-3} ; \mathrm{K}=5,1 \mathrm{mmol}_{\mathrm{c}} \mathrm{dm}^{-3}$; e $\mathrm{MO}=37 \mathrm{~g} \mathrm{~kg}^{-1}$ (Embrapa, 1997).

O delineamento experimental foi de blocos casualizados com cinco repetições, sendo avaliados cinco estados de compactação: PD - plantio direto por oito anos, em um sistema de rotação de culturas envolvendo soja e milho no verão e milho safrinha e aveiapreta no outono/inverno; e PDc1, PDc2, PDc4 e PDc6 - plantio direto com compactação adicional por tráfego de trator em uma, duas, quatro e seis passadas, respectivamente. Por ocasião da instalação do experimento, a cobertura do solo consistia de resíduo de aveia-preta. As parcelas mediram $5 \mathrm{~m}$ de comprimento e 3,6 m de largura, perfazendo uma área total de $18 \mathrm{~m}^{2}$.

A indução à compactação do solo foi realizada no dia 13 de novembro de 2007, dois dias após intensa precipitação pluvial, quando o solo possuía um conteúdo de água próximo à capacidade de campo de $0,28 \mathrm{~kg} \mathrm{~kg}^{-1}$ na camada de $0,0-0,20 \mathrm{~m}$ de profundidade, determinado conforme Embrapa (1997). Foi utilizado um trator agrícola MF 292 (105 cv), com rodado de pneus diagonais e massa total de $5 \mathrm{Mg}$, com pressão de inflação de $96 \mathrm{kPa}$ nos pneus dianteiros (14.9-24 R1) e $110 \mathrm{kPa}$ nos pneus traseiros (18.4-34 R1), sendo $39 \%$ da massa do trator distribuída no eixo dianteiro e $61 \%$ no eixo traseiro. A compactação foi realizada por meio da passagem dos rodados desse trator, perfazendo toda a superfície da parcela, de forma que os pneus comprimissem áreas paralelas entre si.

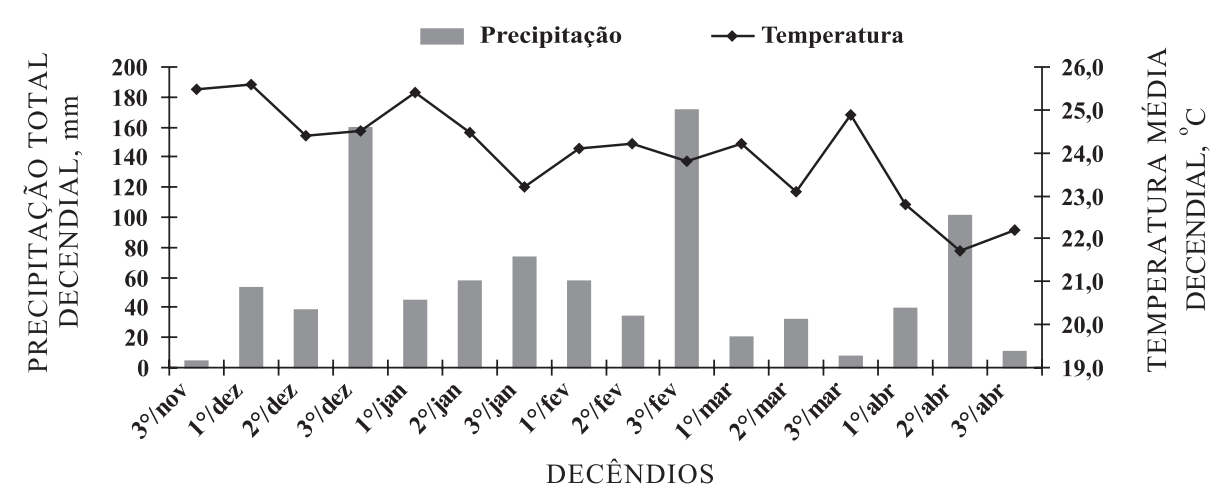

Figura 1. Precipitação pluvial total e temperatura média do ar em cada decêndio na área experimental, no período de novembro de 2007 a abril de 2008. 
O número de vezes que o trator trafegou variou conforme o tratamento; o tráfego foi sobreposto ao anterior, de forma que toda área de cada parcela fosse trafegada com número igual de vezes.

A semeadura do milho (cv. BRS 3150) foi efetuada no dia 22 de novembro de 2007, utilizando-se uma semeadora-adubadora de plantio direto com quatro linhas. O mecanismo sulcador do solo da semeadora foi retirado para não eliminar os possíveis efeitos negativos da compactação, sendo utilizado somente o disco de corte do dosador de sementes. A densidade de semeadura foi de oito sementes por metro, com espaçamento entre linhas de $0,90 \mathrm{~m}$. A adubação consistiu de $0,4 \mathrm{Mg} \mathrm{ha}^{-1}$ da fórmula 10-30-10, para obtenção da produtividade esperada de 6 a $8 \mathrm{Mg} \mathrm{ha}^{-1}$. Decorridos 10 dias da emergência das plântulas, foi realizado o desbaste para cinco plantas por metro. A adubação de cobertura foi realizada 30 dias após a emergência das plântulas, utilizandose $100 \mathrm{~kg} \mathrm{ha}^{-1}$ de $\mathrm{N}$ na forma de sulfato de amônio e $40 \mathrm{~kg} \mathrm{ha}^{-1} \mathrm{de} \mathrm{K}_{2} \mathrm{O}$ na forma de cloreto de potássio. Cada unidade experimental tinha quatro linhas de milho de 5 m de comprimento.

As determinações do sistema radicular foram realizadas quando as plantas de milho estavam no estádio fenológico R1 (Florescimento e Polinização). Em cada parcela foi aberta uma trincheira transversal a uma linha de cultivo, onde a parede vertical da trincheira ficou a $0,05 \mathrm{~m}$ da planta de milho, expondo a raiz desta planta, que foi escolhida aleatoriamente, de maneira que representasse o conjunto de plantas da unidade experimental. Após a exposição das raízes em uma seção transversal à linha de cultivo e próxima ao eixo da planta, o perfil foi dividido em quadrículas de 0,05 m, com auxílio de uma malha de 0,9 × 0,2 m colocada em pleno contato com o solo (Figura 2). Efetuou-se, então, a fotografia do perfil com uma câmera digital (8 megapixels). Essa imagem foi segmentada com a técnica de limiarização (thresholding). Posteriormente, as raízes foram analisadas nas profundidades de $0,0-0,05,0,05-0,10,0,10-0,15$ e $0,15-0,20 \mathrm{~m}$, quanto a comprimento, superfície e diâmetro radicular, pelo programa computacional Delta-T Scan.

Para as determinações de Ds, RP e espaço poroso do solo, foram coletadas amostras com estrutura preservada em cilindros metálicos com $5,57 \mathrm{~cm}$ de diâmetro e $4,1 \mathrm{~cm}$ de altura, nas mesmas profundidades em que se realizou a análise de raízes. As amostras foram retiradas nas entrelinhas da cultura do milho. Em cada parcela e profundidade foram coletadas três subamostras, sendo utilizado o valor médio como representativo.

Após o preparo das amostras, estas foram saturadas por meio da elevação gradual de uma lâmina de água até atingir cerca de dois terços da altura do anel e realizado o procedimento para obtenção da microporosidade pelo método da mesa de tensão, conforme descrito em Embrapa (1997). Essas amostras foram novamente saturadas e submetidas à tensão de 0,01 MPa, em câmaras de Richards, conforme Klute (1986). Esta tensão geralmente tem sido aplicada no solo, para posterior determinação da RP (Smith et al., 1997).

Quando as amostras atingiram o equilíbrio nessa tensão, foi medida a RP, utilizando um penetrógrafo eletrônico com velocidade constante de penetração de $1 \mathrm{~cm} \mathrm{~min}{ }^{-1}$, com diâmetro de base da haste de $4 \mathrm{~mm}$ e semiângulo de $30^{\circ}$, desenvolvido por Serafim et al. (2008). As amostras obtidas nos $5 \mathrm{~mm}$ superiores e inferiores da amostra foram descartadas, visando eliminar o efeito da periferia da amostra (Bradford, 1986). A frequência de leituras de $\mathrm{RP}$ correspondeu à coleta de um valor a cada $0,25 \mathrm{~s}$, obtendo-se 800 leituras por amostra, sendo utilizado o valor médio.

Após a determinação da RP, as amostras foram levadas à estufa a $105-110^{\circ} \mathrm{C}$ por $48 \mathrm{~h}$, para se determinar a umidade volumétrica e a Ds pelo método do anel volumétrico. A porosidade total (Pt) e a macro foram obtidas de acordo com Embrapa (1997).

A distribuição de agregados foi feita para as quatro profundidades do solo, pelo método de peneiramento úmido. Foram retirados blocos de solo com estrutura preservada, secos ao ar e passados em peneiras de 9,52 e $4,76 \mathrm{~mm}$. Os agregados retidos na peneira de $4,76 \mathrm{~mm}$ foram empregados na análise de estabilidade de agregados via úmida, a qual foi realizada colocando as amostras sobre um jogo de peneiras com malhas de $2,0,1,0,0,5$ e $0,105 \mathrm{~mm}$ e submetendo-as a oscilações verticais durante $15 \mathrm{~min}$, numa frequência de 32 oscilações por minuto. Foi adotado, como índices

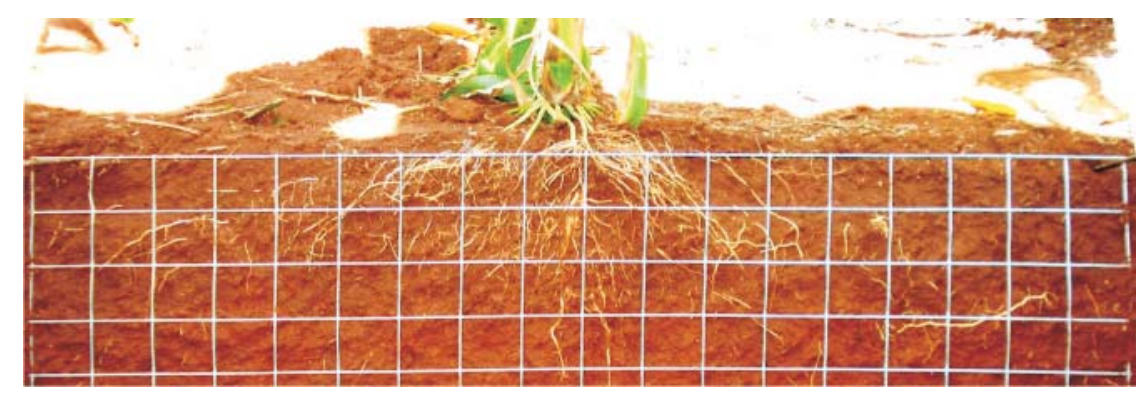

Figura 2. Distribuição radicular do milho em Latossolo Vermelho distroférrico sob plantio direto. A dimensão do perfil estudado é de 0,9 × 0,2 m e cada quadrícula possui 0,05 x 0,05 m. 
de estabilidade, o diâmetro médio geométrico (DMG) e o diâmetro médio ponderado (DMP), cujos cálculos foram feitos segundo Kemper \& Rosenau (1986).

Os resultados foram submetidos à análise de variância e, quando significativa, foi aplicado o teste de Duncan a $5 \%$, para comparação de médias. Também foram realizadas as correlações lineares simples para as combinações duas a duas, dos atributos físicos do solo estudados com o comprimento radicular do milho. Para isso, foi utilizado o aplicativo computacional SAEG (Ribeiro Júnior, 2001).

\section{RESULTADOS E DISCUSSÃO}

O tráfego de trator alterou os atributos físicos do solo somente até $0,10 \mathrm{~m}$ de profundidade (Quadros 1 , 2 e 3), constatando-se que no SPD o tráfego de máquinas provoca aumento expressivo da compactação somente na camada de $0,0-0,10 \mathrm{~m}$ de profundidade, conforme já observado por Secco et al. (2004), Collares et al. (2006) e Freddi et al. (2007). Em subsuperfície $(0,10-0,20 \mathrm{~m})$ foram observados valores altos de densidade do solo em todos os tratamentos (Quadro 1), sendo eles relacionados à ocorrência de um provável "pé-de-grade" nessa camada de solo. Isso faz com que o solo se torne bem estruturado e proporcione maior capacidade de carga, não sendo alterado com o tráfego de trator em até seis passadas.

A Ds nas profundidades de $0,0-0,05$ e $0,05-0,10 \mathrm{~m}$ aumentou a partir da pressão aplicada no solo pelo tráfego em duas passadas (PDc2), em relação ao tratamento sem compactação adicional (PD), no qual o tráfego em quatro (PDc4) e seis vezes (PDc6) não aumentou a Ds, comparando-os com o PDc2. Por sua vez, Streck et al. (2004) e Lima et al. (2006), trabalhando em Argissolo Vermelho distrófico arênico, utilizando quatro passadas de uma máquina de $10 \mathrm{Mg}$, encontraram aumento na Ds em relação ao SPD sem compactação adicional em todas as camadas consideradas no estudo; com duas passadas, Streck et al. (2004) constataram o mesmo nas camadas a partir de $0,15 \mathrm{~m}$.

Isso significa que em solo argiloso, como o utilizado neste trabalho, houve aumento da Ds com duas passadas de trator, enquanto em um solo arenoso, como aquele usado por Streck et al. (2004) e Lima et al. (2006), foram necessários $20 \mathrm{Mg}$ para promover compactação. Além disso, no solo arenoso o efeito da compactação estendeu-se até $0,3 \mathrm{~m}$ de profundidade, ao passo que no argiloso o processo se deu até $0,10 \mathrm{~m}$. Freddi et al. (2007), em Latossolo Vermelho distrófico de textura média, também obtiveram aumento na Ds ocasionada pelo tráfego de tratores de 4 e $11 \mathrm{Mg}$. Observa-se que a Ds entre o PD e PDc1 não foi diferente (Quadro 1), evidenciando que o solo suportou as pressões exercidas pela passagem uma vez da máquina sem aumentar sua Ds.
Latossolos com textura mais arenosa são menos suscetíveis à compactação que aqueles que apresentam predomínio da fração argila. Assim, solos que potencialmente possuem maior qualidade estrutural, associada à menor densidade do solo, serão os mais suscetíveis à degradação. Portanto, é necessário mair cuidado com relação ao uso e manejo para se manter a qualidade física do solo, visando otimizar a produtividade das culturas (Imhoff, 2002).

Poucas variáveis são necessárias para caracterizar o estado de compactação dos solos, sendo o tipo de solo uma das mais importantes (Imhoff, 2002). Os Latossolos são solos com predomínio de caulinita, gibbsita, goethita e hematita (Ferreira et al., 1999) e com presença de uma microestrutura em grânulos, caracterizada por agregados de tamanhos milimétricos. Ferreira et al. (1999) observaram que as propriedades físicas associadas à estrutura foram marcadamente influenciadas pela composição mineralógica da fração argila dos Latossolos. Esses autores relatam ainda que Latossolos cauliníticos apresentaram maior Ds, menor estabilidade de

Quadro 1. Densidade do solo, umidade volumétrica e resistência do solo à penetração em diferentes profundidades e números de passadas de trator em Latossolo Vermelho distroférrico de textura muito argilosa

\begin{tabular}{|c|c|c|c|c|}
\hline \multirow{2}{*}{ Tratamento $^{(1)}$} & \multicolumn{4}{|c|}{ Profundidade (m) } \\
\hline & $0,0-0,05$ & $0,05-0,10$ & $0,10-0,15$ & $0,15-0,20$ \\
\hline & \multicolumn{4}{|c|}{ Densidade do solo $\left(\mathrm{Mg} \mathrm{m}^{-3}\right)$} \\
\hline $\mathrm{PD}$ & $1,12 \mathrm{~b}$ & $1,28 \mathrm{c}$ & $1,30 \mathrm{a}$ & $1,32 \mathrm{a}$ \\
\hline PDc1 & $1,13 \mathrm{~b}$ & $1,30 \mathrm{bc}$ & $1,34 \mathrm{a}$ & $1,33 \mathrm{a}$ \\
\hline PDc2 & $1,21 \mathrm{a}$ & $1,36 \mathrm{ab}$ & $1,35 \mathrm{a}$ & $1,35 \mathrm{a}$ \\
\hline PDc4 & $1,22 \mathrm{a}$ & $1,37 \mathrm{a}$ & $1,35 \mathrm{a}$ & $1,35 \mathrm{a}$ \\
\hline PDc6 & $1,23 \mathrm{a}$ & $1,37 \mathrm{a}$ & $1,36 \mathrm{a}$ & $1,36 \mathrm{a}$ \\
\hline \multirow[t]{2}{*}{$\mathrm{CV}(\%)$} & 3,61 & 4,01 & 3,94 & 3,50 \\
\hline & \multicolumn{4}{|c|}{ Umidade volumétrica $\left(\mathrm{m}^{3} \mathrm{~m}^{-3}\right)^{(2)}$} \\
\hline $\mathrm{PD}$ & $0,35 \mathrm{~b}$ & $0,39 \mathrm{~b}$ & $0,40 \mathrm{a}$ & $0,43 \mathrm{a}$ \\
\hline PDc1 & $0,37 \mathrm{ab}$ & $0,39 \mathrm{~b}$ & $0,42 \mathrm{a}$ & $0,45 \mathrm{a}$ \\
\hline PDc2 & $0,38 \mathrm{a}$ & $0,41 \mathrm{a}$ & $0,42 \mathrm{a}$ & 045 a \\
\hline PDc4 & 0,38 a & $0,42 \mathrm{a}$ & $0,42 \mathrm{a}$ & $0,45 \mathrm{a}$ \\
\hline PDc6 & $0,38 \mathrm{a}$ & $0,42 \mathrm{a}$ & $0,42 \mathrm{a}$ & $0,45 \mathrm{a}$ \\
\hline \multirow[t]{2}{*}{ CV (\%) } & 4,09 & 4,24 & 3,13 & 3,68 \\
\hline & \multicolumn{4}{|c|}{ Resistência do solo à penetração $(\mathrm{MPa})^{(2)}$} \\
\hline $\mathrm{PD}$ & $0,35 \mathrm{~b}$ & $0,63 \mathrm{~b}$ & $0,71 \mathrm{a}$ & $0,65 \mathrm{a}$ \\
\hline PDc1 & $0,36 \mathrm{~b}$ & $0,66 \mathrm{~b}$ & $0,75 \mathrm{a}$ & $0,68 \mathrm{a}$ \\
\hline PDc2 & $0,39 \mathrm{~b}$ & $0,70 \mathrm{~b}$ & $0,77 \mathrm{a}$ & $0,73 \mathrm{a}$ \\
\hline PDc4 & $0,51 \mathrm{a}$ & $0,92 \mathrm{a}$ & $0,84 \mathrm{a}$ & $0,76 \mathrm{a}$ \\
\hline PDc6 & $0,52 \mathrm{a}$ & $0,93 \mathrm{a}$ & $0,85 \mathrm{a}$ & $0,78 \mathrm{a}$ \\
\hline CV (\%) & 19,70 & 15,75 & 12,40 & 13,06 \\
\hline
\end{tabular}

(1) PD: plantio direto sem compactação adicional; PDc1, PDc2, PDc4 e PDc6: correspondem a plantio direto com compactação adicional por tráfego de trator de $5 \mathrm{Mg}$ em uma, duas, quatro e seis passadas, respectivamente. ${ }^{(2)}$ Determinações realizadas em amostras de solo com conteúdo de água retida em capacidade de campo (-0,01 MPa). Médias na coluna, seguidas de mesma letra, não diferem pelo teste de Duncan a $5 \%$. 
agregados em água, menor macro e menor permeabilidade quando comparados com Latossolos gibbsíticos. Assouline et al. (1997) também constataram que Latossolos da região de Cascavel e Palotina (Paraná) apresentaram respostas à compactação diferentes, apesar de possuírem teores de argila semelhantes, o que foi atribuído à estrutura do solo.

A RP, nas profundidades de 0,0-0,05 e 0,05-0,10 m, aumentou com o tráfego do trator; os tratamentos PDc4 e PDc6 apresentaram os maiores valores, não diferindo entre si (Quadro 1). O tráfego de trator em até duas passadas (PDc1 e PDc2) não alterou a RP do solo, comparado ao PD. Resultados semelhantes foram obtidos por Streck et al. (2004), trabalhando com Argissolo Vermelho-Amarelo distrófico arênico trafegado por uma máquina de $10 \mathrm{Mg}$. Esses autores constataram que o tráfego em quatro passadas diferiu dos tratamentos com duas e sem tráfego, aumentando a RP nessas mesmas profundidades. Ribon \& Tavares Filho (2008) confirmam a importância da contribuição da argila na determinação da $\mathrm{RP}$, porém relatam também a importância de se considerar não somente a textura, uma vez que pode haver solos com alta densidade resultante da mineralogia do solo, que resultaria em aumento dos valores de resistência do solo.

Houve incremento de 49 e $48 \%$ nos valores de RP nas profundidades 0,0-0,05 e 0,05-0,10 m, respectivamente, comparando os tratamentos $\mathrm{PD}$ e PDc6. Para Servadio et al. (2005), o aumento no número de passadas do trator aumenta a RP. Zhang et al. (2006), analisando o tráfego em até nove vezes de pequenos tratores (massa de $900 \mathrm{~kg}$ ) no nordeste da China, verificaram aumento na RP com o aumento de passadas do trator, principalmente até $0,10 \mathrm{~m}$ de profundidade. Os valores de RP encontrados no trabalho estão bem abaixo do preconizado como crítico, de 2,0 MPa (Taylor et al., 1966); para Beutler \& Centurion (2004), valores acima de 0,85 MPa em Latossolo Vermelho distrófico textura média já causam danos à produtividade da soja.

Quanto à umidade volumétrica do solo, pôde-se observar seu aumento com as passadas do trator até a profundidade de 0,10 m (Quadro 1). Na profundidade de $0,0-0,05 \mathrm{~m}, \mathrm{o} \mathrm{PD}$ não diferiu do $\mathrm{PDc} 1$, obtendo o menor valor de água volumétrica comparado aos demais tratamentos. Os tratamentos que receberam compactação adicional nessa camada de solo não diferiram quanto à umidade volumétrica. $\mathrm{Na}$ camada de 0,05-0,10 m, o PD e PDc1 obtiveram a menor umidade volumétrica. O aumento na umidade volumétrica do solo pelo aumento nas passadas do trator não pode ser considerado benéfico, pois está relacionado com o aumento na Ds. Deve-se salientar que o conteúdo de água por unidade de volume aumenta com a compactação, sobretudo em tensões de água acima da capacidade de campo (0,01 $\mathrm{MPa})$ (Beutler et al., 2005).

Analisando a Pt e a macro do solo nas camadas de 0,0-0,05 e 0,05-0,10 m de profundidade (Quadro 2), houve reduções nestes atributos pelo aumento do número de passadas - fato não observado para a microporosidade. Os resultados seguem a mesma tendência dos obtidos por Streck et al. (2004) em Argissolo Vermelho-Amarelo distrófico arênico, cultivado em SPD, quando trafegado por diferentes passadas de uma máquina de $10 \mathrm{Mg}$, com pneus radiais com pressão interna de 0,35 $\mathrm{MPa}\left(50 \mathrm{lb} \mathrm{in}^{-2}\right)$.

Adotando que a pressão média que o pneu exerce sobre a superfície do solo é aproximadamente igual à pressão interna dos pneus (Camargo \& Alleoni, 2006), verifica-se que no tratamento com uma passada do trator foi aplicada no solo uma pressão de $110 \mathrm{kPa}$; assim, até esta pressão não ocorrem alterações na $\mathrm{Pt}$ e macro (Quadro 2). Kondo \& Dias Junior (1999), em Latossolo Vermelho muito argiloso cultivado com culturas anuais, verificaram que pressões aplicadas ao solo de até $183 \mathrm{kPa}$ não provocam compactação deste na faixa de friabilidade, pelo fato de a capacidade de suporte de carga do solo não ser excedida.

Verificando os valores de Pt na camada de 0,0 $0,05 \mathrm{~m}$, é possível observar que os tratamentos PD, PDc1 e PDc2 tiveram maior Pt que o PDc6, mas não

Quadro 2. Porosidade total (Pt), macroporosidade (Macro) e microporosidade (Micro) em diferentes profundidades e números de passadas de trator em Latossolo Vermelho distroférrico de textura muito argilosa

\begin{tabular}{|c|c|c|c|c|}
\hline \multirow{2}{*}{ Tratamento $^{(1)}$} & \multicolumn{4}{|c|}{ Profundidade (m) } \\
\hline & $0,0-0,05$ & $0,05-0,10$ & $0,10-0,15$ & $0,15-0,20$ \\
\hline & \multicolumn{4}{|c|}{$\operatorname{Pt}\left(\mathrm{m}^{3} \mathrm{~m}^{-3}\right)$} \\
\hline $\mathrm{PD}$ & $0,62 \mathrm{a}$ & $0,57 \mathrm{a}$ & $0,55 \mathrm{a}$ & $0,54 \mathrm{a}$ \\
\hline PDc1 & $0,62 \mathrm{a}$ & $0,56 \mathrm{ab}$ & $0,54 \mathrm{a}$ & $0,56 \mathrm{a}$ \\
\hline PDc2 & $0,61 \mathrm{ab}$ & $0,55 \mathrm{~b}$ & $0,54 \mathrm{a}$ & $0,55 \mathrm{a}$ \\
\hline PDc4 & $0,59 \mathrm{bc}$ & $0,53 \mathrm{c}$ & $0,53 \mathrm{a}$ & $0,54 \mathrm{a}$ \\
\hline PDc6 & $0,58 \mathrm{c}$ & $0,52 \mathrm{c}$ & $0,54 \mathrm{a}$ & $0,54 \mathrm{a}$ \\
\hline \multirow[t]{2}{*}{$\mathrm{CV}(\%)$} & 2,86 & 2,25 & 3,02 & 2,22 \\
\hline & \multicolumn{4}{|c|}{$\operatorname{Macro}\left(\mathrm{m}^{3} \mathrm{~m}^{-3}\right)$} \\
\hline $\mathrm{PD}$ & $0,23 \mathrm{a}$ & $0,16 \mathrm{a}$ & $0,12 \mathrm{a}$ & $0,10 \mathrm{a}$ \\
\hline PDc1 & $0,23 \mathrm{a}$ & $0,15 \mathrm{ab}$ & $0,11 \mathrm{a}$ & $0,09 \mathrm{a}$ \\
\hline PDc2 & $0,19 \mathrm{~b}$ & $0,13 \mathrm{~b}$ & $0,10 \mathrm{a}$ & $0,08 \mathrm{a}$ \\
\hline PDc4 & $0,17 \mathrm{~b}$ & $0,09 \mathrm{c}$ & $0,10 \mathrm{a}$ & $0,08 \mathrm{a}$ \\
\hline PDc6 & $0,17 \mathrm{~b}$ & $0,09 \mathrm{c}$ & $0,10 \mathrm{a}$ & $0,07 \mathrm{a}$ \\
\hline \multirow[t]{2}{*}{$\mathrm{CV}(\%)$} & 9,18 & 14,56 & 17,09 & 16,38 \\
\hline & \multicolumn{4}{|c|}{$\operatorname{Micro}\left(\mathrm{m}^{3} \mathrm{~m}^{-3}\right)$} \\
\hline $\mathrm{PD}$ & 0,39 a & $0,41 \mathrm{a}$ & $0,43 \mathrm{a}$ & $0,45 \mathrm{a}$ \\
\hline PDc1 & $0,39 \mathrm{a}$ & $0,41 \mathrm{a}$ & $0,43 \mathrm{a}$ & $0,46 \mathrm{a}$ \\
\hline PDc2 & $0,42 \mathrm{a}$ & $0,42 \mathrm{a}$ & $0,44 \mathrm{a}$ & $0,47 \mathrm{a}$ \\
\hline PDc4 & $0,42 \mathrm{a}$ & $0,44 \mathrm{a}$ & $0,43 \mathrm{a}$ & $0,46 \mathrm{a}$ \\
\hline PDc6 & $0,41 \mathrm{a}$ & $0,43 \mathrm{a}$ & $0,44 \mathrm{a}$ & $0,46 \mathrm{a}$ \\
\hline CV $(\%)$ & 4,04 & 4,21 & 3,02 & 3,28 \\
\hline
\end{tabular}

(1) PD: plantio direto sem compactação adicional; PDc1, PDc2, PDc4 e PDc6: correspondem a plantio direto com compactação adicional por tráfego de trator de $5 \mathrm{Mg}$ em uma, duas, quatro e seis passadas, respectivamente. Médias na coluna, seguidas de mesma letra, não diferem pelo teste de Duncan a $5 \%$. 
foram diferentes entre si. Já os resultados PDc4 foram semelhantes aos do PDc2 e PDc6. Na camada de 0,05$0,10 \mathrm{~m}$, o PD obteve o valor mais alto de Pt em relação aos tratamentos com tráfego em mais de duas passadas. Secco et al. (2004), estudando a compactação adicional em SPD em Latossolo Vermelho distroférrico de textura argilosa, verificaram redução da Pt e macro na superfície do solo quando utilizadas três e cinco passadas de um rolo compactador, comparado com o plantio direto sem compactação adicional.

Na camada de 0,0-0,05 m, no PD e PDc1 foram encontrados os maiores valores de macro. A aplicação de maior número de passadas do trator acarretou a redução da macro na camada de $0,05-0,10 \mathrm{~m}$, sendo os tratamentos PDc4 e PDc6 os que apresentaram os menores valores, enquanto no PD e PDc1 estes foram mais elevados (Quadro 2). Com as passadas de trator ocorre diminuição da macro em relação às áreas sem tráfego (Servadio et al., 2005). Comparando o tratamento PD com o PDc4 e PDc6, nas camadas de 0,0-0,05 e 0,05-0,10 m, verifica-se redução na macro de 26 e $44 \%$, respectivamente. Freddi et al. (2007), analisando a camada de 0,0-0,10 m de um Latossolo Vermelho distrófico de textura média, submetido à compactação induzida por um trator de $11 \mathrm{Mg}$, quando o conteúdo de água no solo estava próximo à capacidade de campo (-0,01 $\mathrm{MPa})$, verificaram que a macro foi reduzida de $0,25 \mathrm{~m}^{3} \mathrm{~m}^{-3}$ no solo não trafegado para apenas $0,05 \mathrm{~m}^{3} \mathrm{~m}^{-3}$ nos tratamentos com quatro e seis passadas do trator.

Os valores de macro foram inferiores a $0,10 \mathrm{~m}^{3} \mathrm{~m}^{-3}$ nos tratamentos PDc4 e PDc6 na camada de 0,050,10 m (Quadro 2), indicando prováveis limitações ao arejamento do solo em épocas mais úmidas, como relatado por Collares et al. (2008). Feng et al. (2002) afirmam que esse valor para solos argilosos já causa inibição ao suprimento adequado de $\mathrm{O}_{2}$ às plantas, sendo necessários valores mais altos que $0,10 \mathrm{~m}^{3} \mathrm{~m}^{-3}$ de porosidade de aeração. Entretanto, de maneira geral, o valor dado como crítico para as plantas é de $0,10 \mathrm{~m}^{3} \mathrm{~m}^{-3}$ (Pagliai et al., 2003).

A estabilidade de agregados medida pelo DMG e DMP nas camadas de 0,0-0,05 e 0,05-0,10 m foi alterada pelos tratamentos aplicados (Quadro 3), sendo observado aumento no DMG e DMP com o aumento das passadas de trator. Os valores de diâmetro médio de agregados encontrados neste trabalho estão próximos aos encontrados por Corrêa (2002) em Latossolo Vermelho-Amarelo sob plantio direto.

No tratamento PD foi encontrado o menor valor de DMG na camada de 0,0-0,10 m. A compactação no SPD pelo tráfego de trator aumentou o DMG, sendo observados na camada de 0,0-0,05 m os maiores valores nos tratamentos PDc4 e PDc6; na camada de 0,05-0,10 m, os maiores valores foram obtidos em PDc2, PDc4 e PDc6 (Quadro 3). Silva et al. (2006) encontraram resultados semelhantes quando trabalharam com pressões de compactação de até $120 \mathrm{kPa}$ em Latossolo Vermelho-Amarelo argiloso.
Quadro 3. Diâmetro médio geométrico e diâmetro médio ponderado em diferentes profundidades e números de passadas de trator em Latossolo Vermelho distroférrico de textura muito argilosa

\begin{tabular}{lcccc}
\hline & \multicolumn{4}{c}{ Profundidade (m) } \\
\cline { 2 - 5 } Tratamento $^{(\mathbf{1})}$ & \multicolumn{5}{c}{ Diâmetro médio geométrico (mm) } \\
\cline { 2 - 5 } & $\mathbf{0 , 0 - 0 , 0 5}$ & $\mathbf{0 , 0 5 - 0 , 1 0}$ & $\mathbf{0 , 1 0 - 0 , 1 5}$ & $\mathbf{0 , 1 5 - 0 , 2 0}$ \\
\hline PD & $2,64 \mathrm{c}$ & $2,67 \mathrm{c}$ & $2,77 \mathrm{a}$ & $2,76 \mathrm{a}$ \\
PDc1 & $2,67 \mathrm{~b}$ & $2,72 \mathrm{~b}$ & $2,78 \mathrm{a}$ & $2,77 \mathrm{a}$ \\
PDc2 & $2,69 \mathrm{~b}$ & $2,76 \mathrm{a}$ & $2,78 \mathrm{a}$ & $2,77 \mathrm{a}$ \\
PDc4 & $2,71 \mathrm{a}$ & $2,77 \mathrm{a}$ & $2,78 \mathrm{a}$ & $2,78 \mathrm{a}$ \\
PDc6 & $2,72 \mathrm{a}$ & $2,78 \mathrm{a}$ & $2,78 \mathrm{a}$ & $2,78 \mathrm{a}$ \\
CV (\%) & 0,56 & 0,58 & 0,46 & 0,49 \\
& Diâmetro médio ponderado (mm) \\
PD & $2,78 \mathrm{~d}$ & $2,79 \mathrm{c}$ & $2,83 \mathrm{a}$ & $2,81 \mathrm{a}$ \\
PDc1 & $2,79 \mathrm{~cd}$ & $2,81 \mathrm{~b}$ & $2,84 \mathrm{a}$ & $2,82 \mathrm{a}$ \\
PDc2 & $2,80 \mathrm{bc}$ & $2,82 \mathrm{ab}$ & $2,84 \mathrm{a}$ & $2,82 \mathrm{a}$ \\
PDc4 & $2,81 \mathrm{ab}$ & $2,83 \mathrm{a}$ & $2,85 \mathrm{a}$ & $2,84 \mathrm{a}$ \\
PDc6 & $2,82 \mathrm{a}$ & $2,83 \mathrm{a}$ & $2,85 \mathrm{a}$ & $2,84 \mathrm{a}$ \\
CV (\%) & 0,44 & 0,36 & 0,49 & 0,65 \\
\hline
\end{tabular}

(1) PD: plantio direto sem compactação adicional; PDc1, PDc2, PDc4 e PDc6: correspondem a plantio direto com compactação adicional por tráfego de trator de $5 \mathrm{Mg}$ em uma, duas, quatro e seis passadas, respectivamente. Médias na coluna, seguidas de mesma letra, não diferem pelo teste de Duncan a $5 \%$.

O DMP apresentou resultados semelhantes aos do DMG (Quadro 3). Na camada de 0,0-0,05 m, os menores valores de DMP foram encontrados no PD e PDc1; o maior valor foi obtido no PDc6, não diferindo significativamente do PDc4. Para a camada de 0,050,10 m, o PD mostrou o menor valor de DMP, diferindo dos demais tratamentos com compactação adicional. Já os maiores valores de DMP foram encontrados no PDc2, PDc4 e PDc6. Calonego \& Rosolem (2008), analisando sistemas de manejo, observaram que na camada de 0,05-0,10 m o DMP é aumentado com o SPD e com o cultivo de plantas de cobertura, em comparação com o solo escarificado.

Esse aumento na estabilidade de agregados verificada pelo aumento no DMG e DMP, com a compactação adicional no solo em SPD, pode ser atribuído à provável agregação mecânica que ocorre por efeito da tensão exercida pela compactação, levando à união de partículas sob alta umidade no solo. Silva et al. (2006) constataram que esse processo foi detectado em Latossolo Vermelho-Amarelo argiloso.

A compactação do solo influenciou negativamente o comprimento radicular (CR), a superfície radicular (SR) e o diâmetro médio radicular (DR), em todas as profundidades (Quadro 4).

Foloni et al. (2003) também verificaram, em Latassolo Vermelho distroférrico textura média, reduções na massa da matéria seca e densidade do comprimento radicular de plantas de milho na camada de solo compactada. Analisando a densidade de raízes 
Quadro 4. Comprimento radicular, superfície radicular e diâmetro médio radicular das raízes de milho em diferentes profundidades e números de passadas de trator em Latossolo Vermelho distroférrico textura muito argilosa

\begin{tabular}{|c|c|c|c|c|}
\hline \multirow{2}{*}{ Tratamento $^{(1)}$} & \multicolumn{4}{|c|}{ Profundidade (m) } \\
\hline & $0,0-0,05$ & $0,05-0,10$ & $0,10-0,15$ & $0,15-0,20$ \\
\hline & \multicolumn{4}{|c|}{ Comprimento radicular $\left(\mathrm{m} \mathrm{m}^{-2}\right)$} \\
\hline PD & $101,11 \mathrm{a}$ & $69,40 \mathrm{a}$ & $31,68 \mathrm{a}$ & $17,68 \mathrm{a}$ \\
\hline PDc1 & $55,38 \mathrm{~b}$ & $24,95 \mathrm{~b}$ & $11,75 \mathrm{~b}$ & $6,94 \mathrm{~b}$ \\
\hline PDc2 & $21,71 \mathrm{c}$ & $13,24 \mathrm{bc}$ & $8,39 \mathrm{bc}$ & $4,83 \mathrm{bc}$ \\
\hline PDc4 & $20,05 \mathrm{c}$ & $9,75 \mathrm{bc}$ & $6,12 \mathrm{bc}$ & $3,80 \mathrm{bc}$ \\
\hline PDc6 & $16,44 \mathrm{c}$ & $7,76 \mathrm{c}$ & $4,61 \mathrm{c}$ & $2,80 \mathrm{c}$ \\
\hline \multirow[t]{2}{*}{ CV (\%) } & 37,39 & 45,83 & 37,69 & 38,36 \\
\hline & \multicolumn{4}{|c|}{ Superfície radicular $\left(\mathrm{cm} \mathrm{m}^{-2}\right)$} \\
\hline PD & $830,87 \mathrm{a}$ & $599,27 \mathrm{a}$ & $281,62 \mathrm{a}$ & $171,86 \mathrm{a}$ \\
\hline PDc1 & $611,31 \mathrm{~b}$ & $298,06 \mathrm{~b}$ & $134,41 \mathrm{~b}$ & $81,23 \mathrm{~b}$ \\
\hline PDc2 & $241,91 \mathrm{c}$ & $132,96 \mathrm{c}$ & $82,47 \mathrm{bc}$ & $48,25 \mathrm{bc}$ \\
\hline PDc4 & $219,60 \mathrm{c}$ & $110,28 \mathrm{c}$ & $69,22 \mathrm{c}$ & $37,52 \mathrm{c}$ \\
\hline PDc6 & $165,22 \mathrm{c}$ & $76,42 \mathrm{c}$ & $41,70 \mathrm{c}$ & $25,63 \mathrm{c}$ \\
\hline \multirow[t]{2}{*}{ CV (\%) } & 38,59 & 40,75 & 36,25 & 40,52 \\
\hline & \multicolumn{4}{|c|}{ Diâmetro de raiz (mm) } \\
\hline $\mathrm{PD}$ & $0,97 \mathrm{a}$ & $1,00 \mathrm{a}$ & $0,99 \mathrm{a}$ & $0,96 \mathrm{a}$ \\
\hline PDc1 & $0,98 \mathrm{a}$ & $1,01 \mathrm{a}$ & $0,94 \mathrm{ab}$ & $0,87 \mathrm{a}$ \\
\hline $\mathrm{PDc} 2$ & $0,92 \mathrm{ab}$ & $0,82 \mathrm{~b}$ & $0,76 \mathrm{bc}$ & $0,74 \mathrm{~b}$ \\
\hline PDc4 & $0,82 \mathrm{bc}$ & $0,89 \mathrm{ab}$ & $0,82 \mathrm{abc}$ & $0,70 \mathrm{~b}$ \\
\hline PDc6 & $0,70 \mathrm{c}$ & $0,78 \mathrm{~b}$ & $0,71 \mathrm{c}$ & $0,69 \mathrm{~b}$ \\
\hline CV (\%) & 10,35 & 13,40 & 15,18 & 9,44 \\
\hline
\end{tabular}

(1) PD: plantio direto sem compactação adicional; PDc1, PDc2, PDc4 e PDc6: correspondem a plantio direto com compactação adicional por tráfego de trator de $5 \mathrm{Mg}$ em uma, duas, quatro e seis passadas, respectivamente. Médias na coluna, seguidas de mesma letra, não diferem pelo teste de Duncan a $5 \%$.

de soja em Latossolo Vermelho distrófico textura média com o aumento do número de passadas que a máquina trafegou sobre o solo, Beutler \& Centurion (2004) observaram decréscimo linear na camada de 0,05$0,15 \mathrm{~m}$, com menores alterações na camada de $0,15-$ $0,20 \mathrm{~m}$.

O CR e SR, em todas as profundidades, foram maiores no $\mathrm{PD}$, e os menores valores sempre foram obtidos nos tratamentos PDc2, PDc4 e PDc6. O CR e SR estão correlacionados de forma significativa $(p<0,01)$ e positiva $(r=0,98)$, por isso nota-se a semelhança encontrada entre os seus resultados.

Analisando a camada de 0,0-0,20 m, observaramse reduções do comprimento médio de raízes de 55 , 78, 82 e $86 \%$ no PDc1, PDc2, PDc4 e PDc6, respectivamente, comparado com o PD. Guimarães \& Moreira (2001) encontraram redução de 41,2 \% na densidade de raiz de arroz na camada de solo compactada $(0,0-0,20 \mathrm{~m})$. Sabendo que a diminuição em $40 \%$ do CR é crítica à produtividade das plantas (Pabin et al., 1998), nota-se que em todos os tratamentos com compactação adicional esse valor foi extrapolado, podendo limitar a capacidade das plantas em expressar todo o seu potencial produtivo. Analisando os resultados, também é possível observar que, na média dos tratamentos, $77 \%$ do CR encontrase na camada de 0,0-0,10 m.
O CR correlacionou-se de modo significativo $(\mathrm{p}<0,01)$ e positivo com a macro $(\mathrm{r}=0,72)$ e negativo com a Ds $(r=-0,62)$ e RP $(r=-0,59)$ (Figura 3$)$.

Mesmo com valores de RP abaixo de 1,10 MPa, o sistema radicular do milho sofreu expressiva redução em seu comprimento. Isso pode estar relacionado ao conteúdo de água (capacidade de campo) em que se foi medida a RP, pois no campo há intensas variações no conteúdo de água do solo, podendo ele ser reduzido, fazendo com que rapidamente a $\mathrm{RP}$ passe de uma condição não limitante para limitante, influenciando negativamente o crescimento das raízes. Gonçalves et al. (2006), em Latossolo Vermelho distroférrico textura muito argilosa em casa de vegetação, verificaram que a cultura do milheto apresentou, na camada compactada, diminuição da densidade do comprimento radicular com o aumento da Ds e RP; a partir da $\mathrm{Ds}$ de $1,18 \mathrm{Mg} \mathrm{m}^{-3}$ e RP de $0,12 \mathrm{MPa}$ já houve reduções no crescimento das raízes. Para Rosolem et al. (1999), o crescimento das raízes primárias de milho é reduzido pela metade quando a $\mathrm{RP}$ atinge 0,33 $\mathrm{MPa}$.

O aumento da RP e Ds causou redução linear do CR (Figura 3). Beutler \& Centurion (2004), trabalhando em Latossolo Vermelho distroférrico textura média, e Cardoso et al. (2006), em Latossolo Vermelho distroférrico muito argiloso, relatam que 


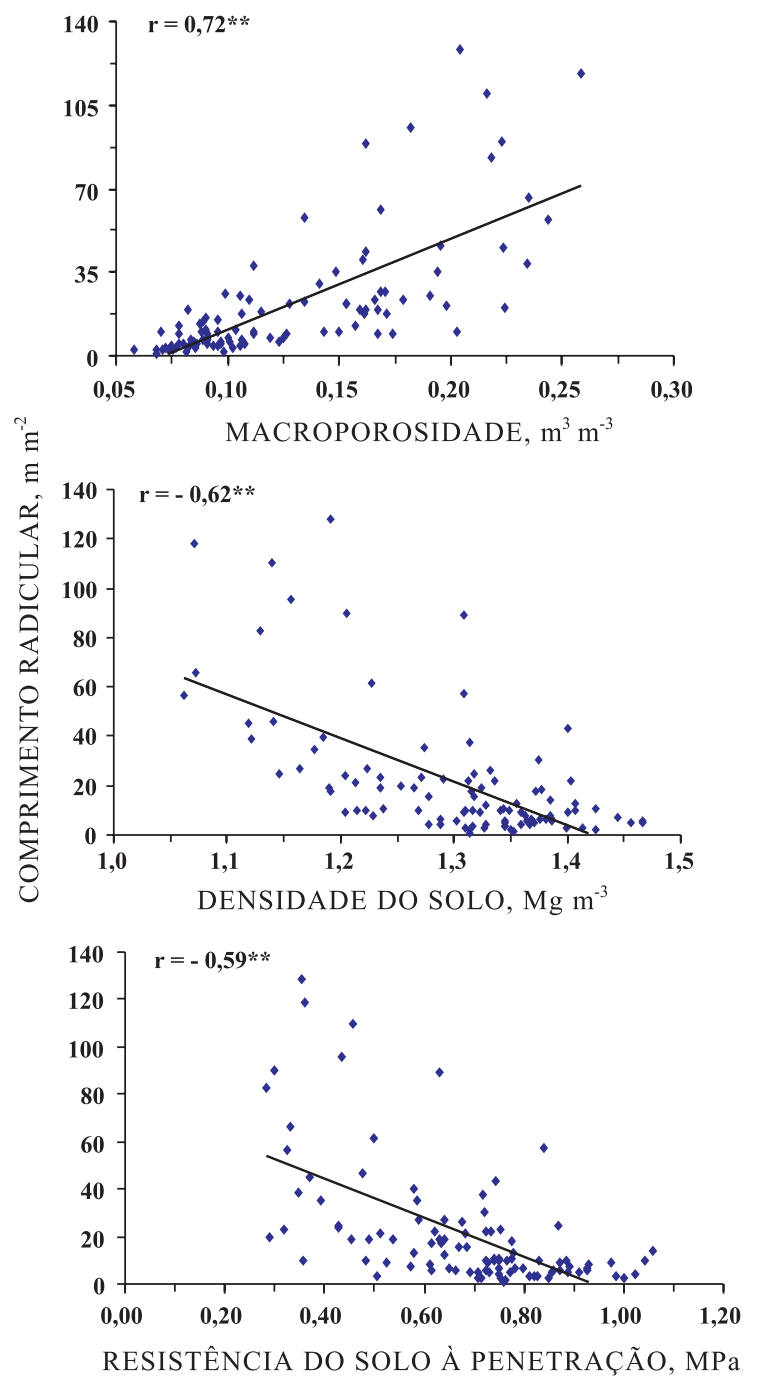

Figura 3. Comprimento radicular de acordo com a macroporosidade, densidade do solo e resistência do solo à penetração em Latossolo Vermelho distroférrico de textura muito argilosa. **significativo pelo teste t a $1 \%$. Camada de 0,0-0,20 m $(\mathrm{n}=100)$.

camadas de solo onde ocorre aumento da RP proporcionam decréscimo linear da densidade de raízes. Analisando o sistema radicular do milho, Rosolem et al. (1999) verificaram que o aumento da Ds de 1,07 a $1,38 \mathrm{Mg} \mathrm{m}^{-3}$ em Latossolo com $48 \%$ de argila reduziu linearmente o comprimento da raiz seminal primária.

Pode-se observar (Figura 3) a importância da Macro sobre o crescimento do sistema radicular do milho, comparado com os demais atributos físicos do solo, mostrando que as raízes de milho crescem pelos espaços dos macroporos, o que corrobora os resultados obtidos por Abreu et al. (2004) e Servadio et al. (2005). Estabelecendo o limite crítico de macro de $0,10 \mathrm{~m}^{3} \mathrm{~m}^{-3}$, pode-se observar que nesta porosidade já se encontra uma condição desfavorável ao crescimento radicular.
As correlações da macro, Ds e RP com o CR do milho evidenciam que, quando os valores desses atributos do solo estão mais distantes dos considerados críticos, o CR do milho é pouco influenciado por eles, sendo isso comprovado pela maior dispersão dos dados. Observa-se que a macro do solo a partir de $0,16 \mathrm{~m}^{3} \mathrm{~m}^{-3}$ tem pouca influência sobre o CR do milho; quando os valores estão abaixo desse, nota-se pequena dispersão entre os dados, evidenciando elevada atuação da macro sobre o CR do milho. Para a Ds e RP, foram observados que valores a partir de $1,32 \mathrm{Mg} \mathrm{m}^{-3}$ e $0,64 \mathrm{MPa}$, respectivamente, são mais exatos para descrever a influência desses atributos sobre o CR do milho.

Com relação ao DR, observa-se que a compactação do solo reduziu os valores desse atributo em todas as profundidades (Quadro 4). Quando considerada a camada de 0,0-0,20 m, os tratamentos PD e PDc1 foram semelhantes entre si, apresentando sempre os maiores DR. Os tratamentos PDc4 e PDc6 também foram semelhantes, mas com os valores de DR reduzidos. Essa redução no DR pode ser uma adaptação das plantas às condições restritivas impostas pela compactação, para que as raízes possam penetrar no espaço poroso do solo de menor diâmetro, a fim de obter água e nutrientes para o seu crescimento e desenvolvimento. Clark et al. (2003) afirmam que há formação de raízes laterais com menor diâmetro para penetrar em pequenos poros. Collares et al. (2008) também observaram, em SPD compactado, o surgimento de raízes secundárias e mais finas de feijão.

\section{CONCLUSÕES}

1. O aumento da compactação do solo induzida pelo tráfego de trator a partir de duas passadas $(220 \mathrm{kPa})$ promove aumento da densidade do solo e redução da macroporosidade e porosidade total; a partir de quatro passadas (440 kPa), promove aumento da resistência do solo à penetração de maneira efetiva, até $0,10 \mathrm{~m}$ de profundidade.

2. A compactação adicional influencia negativamente o sistema radicular do milho, sendo a macroporosidade o indicador de qualidade do solo mais bem relacionado com o comprimento e a superfície radicular.

\section{AGRADECIMENTOS}

À Capes, pela concessão da bolsa de estudos que tornou possível a realização deste trabalho.

\section{LITERATURA CITADA}

ABREU, S.L.; REICHERT, J.M. \& REINERT, D.J. Escarificação mecânica e biológica para redução da compactação em Argissolo franco-arenoso sob plantio direto. R. Bras. Ci Solo, 28:519-531, 2004. 
ASSOULINE, S.; TAVARES, J. \& TESSIER, D. Effect of compaction on soil physical and hydraulic properties: Experimental results and modeling. Soil Sci. Soc. Am. J., 61:390-398, 1997.

BEUTLER, A.N.; SILVA, M.L.N.; CURI, N.; FERREIRA, M.M.; CRUZ, J.C. \& PEREIRA FILHO, I.A. Resistência à penetração e permeabilidade de Latossolo Vermelho distrófico típico sob sistemas de manejo na região dos cerrados. R. Bras. Ci Solo, 25:167-177, 2001.

BEUTLER, A.N.; CENTURION, J.F. \& SILVA, A.P. Intervalo hídrico ótimo e a produção de soja e arroz em dois Latossolos. Irriga, 9:181-192, 2004.

BEUTLER, A.N. \& CENTURION, J.F. Compactação do solo no desenvolvimento radicular e na produtividade da soja. Pesq. Agropec. Bras., 39:581-588, 2004.

BeUtler, A.N.; CENTURION, J.F.; FREDDi, O.S. \& ANDRIOLI, I. Efeito da compactação do solo na estabilidade de agregados e no conteúdo gravimétrico de água. Acta Sci. Agron., 27:193-198, 2005.

BEUTLER, A.N.; CENTURION, J.F.; CENTURION, M.A.P.C.; LEONEL, C.L.; SÃO JOÃO, A.C.G. \& FREDDI, O.S. Intervalo hídrico ótimo no monitoramento da compactação e da qualidade física de um Latossolo Vermelho cultivado com soja. R. Bras. Ci Solo, 31:1223$1232,2007$.

BRADFORD, J.M. Penetrability. In: KLUTE, A., ed. Methods of soil analysis. 2.ed. Madison, American Society of Agronomy, 1986. p.463-478.

CALONEGO, J.C. \& ROSOLEM, C.A. Estabilidade de agregados do solo após manejo com rotação de culturas e escarificação. R. Bras. Ci Solo, 32:1399-1407, 2008.

CAMARGO, O.A. \& ALLEONI, L.R.F. Causas da compactação do solo. 2006. Disponível em: <http://www.infobibos.com/ Artigos/CompSolo/C3/Comp3.htm>. Acesso em: 15 abr. 2009.

CARDOSO, E.G.; ZOTARELLI, L.; PICCININ, J.L.; TORRES, E.; SARAIVA, O.F. \& GUIMARÃES, M.F. Sistema radicular da soja em função da compactação do solo no sistema plantio direto. Pesq. Agropec. Bras., 41:493-501, 2006.

CLARK, L.J.; WHALLEY, W.R. \& BARRACLOUGH, P.B. How do roots penetrate strong soil? Plant Soil, 255:93-104, 2003.

COLLARES, G.L.; REINERT, D.J.; REICHERT, J.M. \& KAISER, D.R. Qualidade física do solo na produtividade da cultura do feijoeiro num Argissolo. Pesq. Agropec. Bras., 41:1663-1674, 2006.

COLLARES, G.L.; REINERT, D.J.; REICHERT, J.M. \& KAISER, D.R. Compactação de um Latossolo induzida pelo tráfego de máquinas e sua relação com o crescimento e produtividade de feijão e trigo. R. Bras. Ci. Solo, 32:933942, 2008.

CORRÊA, J.C. Efeito de sistemas de cultivo na estabilidade de agregados de um Latossolo Vermelho-Amarelo em Querência, MT. Pesq. Agropec. Bras., 37:203-209, 2002.
EMPRESA BRASILEIRA DE PESQUISA AGROPECUÁRIA EMBRAPA. Centro Nacional de Pesquisa de Solos. Manual de métodos de análise de solo. 2.ed. Rio de Janeiro, 1997. $212 \mathrm{p}$

FENG, G.; WU, L. \& LETEY, J. Evaluating aeration criteria by simultaneous measurement of oxygen diffusion rate and soil-water regime. Soil Sci., 167:495-503, 2002.

FERREIRA, M.M.; FERNANDES, B. \& CURI, N. Influência da mineralogia da fração argila nas propriedades físicas de Latossolos da Região Sudeste do Brasil. R. Bras. Ci. Solo, 23:515-524, 1999.

FOLONI, J.S.S.; CALONEGO, J.C. \& LIMA, S.L. Efeito da compactação do solo no desenvolvimento aéreo e radicular de cultivares de milho. Pesq. Agropec. Bras., 38:947-953, 2003 .

FREDDI, O.S.; CENTURION, J.F.; BEUTLER, A.N.; ARATANI, R.G. \& LEONEL, C.L. Compactação do solo no crescimento radicular e produtividade da cultura do milho. R. Bras. Ci. Solo, 31:627-636, 2007.

GENRO JUNIOR, S.A.; REINERT, D.J. \& REICHERT, J.M. Variabilidade temporal da resistência à penetração de um Latossolo Argiloso sob semeadura direta com rotação de culturas. R. Bras. Ci. Solo, 28:477-484, 2004.

GONÇALVES, W.G.; JIMENEZ, R.L.; ARAÚJO FILHO, J.V.; ASSIS, R.L.; SILVA, G.P.; FÁBIO R. \& PIRES, F.R. Sistema radicular de plantas de cobertura sob compactação do solo. Eng. Agric., 26:67-75, 2006.

GUIMARÃES, C.M. \& MOREIRA, J.A.A. Compactação do solo na cultura do arroz de terras altas. Pesq. Agropec. Bras., 36:703-707, 2001

IMHOFF, S.D.C. Indicadores de qualidade estrutural e trafegabilidade de Latossolos e Argissolos Vermelhos. Piracicaba, Escola Superior Luiz de Queiroz, 2002. 94p. (Tese de Doutorado)

KEMPER, W.D. \& ROSENAU, R.C. Aggregate stability and size distribution. In: KLUTE, A., ed. Methods of soil analysis. 2.ed. Madison, American Society of Agronomy, 1986. p.425-441.

KLUTE, A. Water retention: Laboratory methods. In: KLUTE, A., ed. Methods of soil analysis. 2.ed. Madison, American Society of Agronomy, 1986. p.635-662.

KONDO, M.K. \& DIAS JUNIOR, M.S. Estimativa do efeito do uso e da umidade do solo sobre a compactação adicional de três Latossolos. R. Bras. Ci. Solo, 23:211-218, 1999.

LIMA, C.L.R.; REINERT, D.J.; REICHERT, J.M. \& SUZUKI, L.E.A.S. Compressibilidade de um Argissolo sob plantio direto escarificado e compactado. Ci. Rural, 36:1765-1772, 2006.

LLANILLO, R.F.; RICHART, A.; TAVARES FILHO, J.; GUIMARÃES, M.F. \& FERREIRA, R.R.M. Evolução de propriedades físicas do solo em função dos sistemas de manejo em culturas anuais. Semina: Ci. Agr., 27:205220,2006 
PABIN, J.; LIPIEC, J.; WLODEK, S.; BISKUPSKI, A. \& KAUS, A. Critical soil bulk density and strength for pea seedling root growth as related to other soil factors. Soil Till. Res. 46:203-208, 1998.

PAGLIAI, M.; MARSILI, A.; SERVADIO, P.; VIGNOZZI, N. \& PELLEGRINI, S. Changes in some physical properties of a clay soil in Central Italy following the passage of rubber tracked and wheeled tractors of medium power. Soil Till. Res., 73:119-129, 2003.

RAPER, R.L. Agricultural traffic impacts on soil. J. Terramech., 42:259-280, 2005.

RIBEIRO JÚNIOR, J.I. Análises estatísticas no SAEG. Viçosa, MG, Universidade Federal de Viçosa, 2001. 301p.

RIBON, A.P. \& TAVARES FILHO, J. Estimativa da resistência mecânica à penetração de um Latossolo Vermelho sob cultura perene no norte do Estado do Paraná. R. Bras. Ci. Solo, 32:1817-1825, 2008

ROSOLEM, C.A.; FERNANDEZ, E.M.; ANDREOTTI, M. \& CRUSCIOL, C.A.C. Crescimento radicular de plântulas de milho afetado pela resistência do solo à penetração. Pesq. Agropec. Bras., 34:821-828, 1999.

SECCO, D.; REINERT, D.J.; REICHERT, J.M. \& DA ROS, C.O. Produtividade de soja e propriedades físicas de um Latossolo submetido a sistemas de manejo e compactação. R. Bras. Ci. Solo, 28:797-804, 2004.

SERAFIM, M.E. Desenvolvimento de um penetrógrafo de bancada visando a determinação do intervalo hídrico ótimo (IHO) em diferentes sistemas de produção. Dourados, Universidade Federal da Grande Dourados, 2007. 79p. (Tese de Mestrado)
SERAFIM, M.E.; VITORINO, A.C.T.; SOUZA, C.M.A.; PRADO, E.D.; VENTURIN, J.C. \& YAMAMOTO, N.T. Desenvolvimento de um penetrógrafo eletromecânico de bancada. R. Ci. Téc. Agropec., 17:61-65, 2008.

SERVADIO, P.; MARSILI, A.; VIGNOZZI, N.; PELLEGRINI, S. \& PAGLIAI, M. Effects on some soil qualities in Central Italy following the passage of four wheel drive tractor fitted with single and dual tires. Soil Till. Res., 84:87-100, 2005 .

SILVA, S.R.; BARROS, N.F. \& COSTA, L.M. Atributos físicos de dois Latossolos afetados pela compactação do solo. R. Bras. Eng. Agríc. Amb., 10:842-847, 2006.

SMITH, C.W.; JOHNSTON, M.A. \& LORENTZ, S. The effect of soil compaction and soil physical properties on the mechanical resistance of South African forestry soils. Geoderma, 78:93-111, 1997.

STRECK, C.A.; REINERT, D.J.; REICHERT, J.M. \& KAISER, D.R. Modificações em propriedades físicas com a compactação do solo causada pelo tráfego induzido de um trator em plantio direto. Ci. Rural, 34:755-760, 2004.

TAVARES FILHO, J.; BARBOSA, G.M.; GUIMARÃES, M.F. \& FONSECA, I.C.B. Resistência à penetração e desenvolvimento do sistema radicular do milho (Zea mays) sob diferentes sistemas de manejo em um Latossolo Roxo. R. Bras. Ci. Solo, 25:725-730, 2001.

TAYLOR, H.M.; ROBERSON, G.M. \& PARKER JÚNIOR, J.J. Soil strength-root penetration relations to medium to coarse-textured soil materials. Soil Sci., 102:18-22, 1966.

ZHANG, X.Y.; CRUSE, R.M.; SUI, Y.Y. \& JHAO, Z. Soil compaction induced by small tractor traffic in Northeast China. Soil Sci. Soc. Am. J., 70:613-619, 2006. 